\title{
Correction to: Modeling of Parameters of Laser Surfacing Zones and Determination of Tribotechnical Properties of Coatings Obtained by Laser Additive Technologies
}

Vladimir Biryukov $\mathbb{C}$

Correction to:

Chapter "Modeling of Parameters of Laser Surfacing Zones and Determination of Tribotechnical Properties of Coatings Obtained by Laser Additive Technologies" in: A. Mottaeva (ed.): Technological Advancements in Construction, Lecture Notes in Civil Engineering 180, https://doi.org/10.1007/978-3-030-83917-8_46

In the original version of this book, the following belated correction has been incorporated in Chapter 46: The author name has been changed from "Biryukov Vladimir" to "Vladimir Biryukov". 